\title{
DIMENSÕES E PERSPECTIVAS DOS DIREITOS HUMANOS: ENSINO SUPERIOR DAS FACULDADES PARTICULARES DE ANÁPOLIS GOIÁS
}

\author{
Rildo Mourão Ferreira ${ }^{1}$ \\ Vanessa Vilela de Sá ${ }^{2}$
}

\section{Resumo}

O presente artigo tem como o objetivo de traçar os panoramas axiológicos e normativos da Ciência dos Direitos Humanos, bem como verificar a influência e a importância destes direitos na formação em ensino superior nas universidades de Anápolis Goiás. Na alvorada do trabalho, justifica-se a esmiuçar os pilares que propiciaram o surgimento da Ciência dos Direitos Humanos através do método dialético-histórico. Nessa esteira, busca-se a compreensão da processualística da formação dos tratados internacionais sobre direitos humanos e a incorporação dos venerandos documentos ao sistema jurídico brasileiro. Ao final, consubstanciou-se a aplicação dos fundamentos dos direitos humanos à formação do corpo discente no bojo dos cursos de graduação através da observação e da pesquisa de campo realizada em estabelecimento de ensino superior na cidade de Anápolis, com a comprovação e preocupação em considerar de suma importância na capacitação contínua do corpo docente por meio do cotejamento à Ciência dos Direitos Humanos como coluna dorsal das matrizes curriculares. Para atingir esses objetivos foram empregados os métodos dialético-comparativo, por meio de pesquisa, análise e síntese em textos normativos e legislativos, dispositivos jurisprudenciais e preleções doutrinárias, e a aplicação de testes para averiguar a aplicação dos vetores conceituais aos cursos de graduação em Instituições de Ensino na Cidade de Anápolis Goiás.

Palavras-chave: Direitos Humanos; Direitos Fundamentais; Ensino Superior; Dimensões e Perspectiva; Tratados

\section{INTRODUÇÃO}

O presente artigo se erigirá com o objetivo de verificar os reflexos das Ciências dos Direitos Humanos na formação acadêmica no ensino superior ante a aplicação e adesão às diretrizes curriculares dos cursos das faculdades particulares de Anápolis Goiás. Ocorre que a questão de fundo que envolve e que deve sim recuperar as dimensões nas faculdades que não existe de acordo com a pesquisa.

Vale destacar na pesquisa, que os dados coletados foram de fevereiro de 2015 a julho de 2016.

Será demonstrada a evolução histórica dos Direitos Humanos até os dias atuais, como esses Direitos chegaram ao Brasil e quando foram definitivamente tratados com suma importância pelos legisladores, destaque-se ainda que somente após uma longa jornada internacional é que em 1988 o Brasil começou a tratar de forma efetiva o

\footnotetext{
${ }^{1}$ Professor e Pesquisador do Programa de Pós-Graduação em Sociedade, Tecnologia e Meio Ambiente da Unievangélica de Anápolis Goiás. Pós-Doutor em Desenvolvimento Sustentável pela UNB. E-mail: rildomourao@uol.com.br

${ }^{2}$ Pós-graduada Lato Sensu em Docência Universitária, pela Faculdade Católica de Anápolis e Pós-graduada em Direito Processo Civil pela Faculdade Damásio S.A. E-mail: vanessavilelaaha@hotmail.com
} 
respeito a dignidade da pessoa humana, salientar que não só o Brasil mas como outros países vem apresentando evoluções mais ainda há muito o que melhorar.

Os fundamentos doutrinários dos professores Boaventura Santos (2004 e 2006), George Yúdice (2004), Pierre Bourdieu (2005), Flávia Piovesan (1996), Henkin (2002), Michael Apple (1998) e Valério de Oliveira Mazzuoli (2006) servirão de norteadores para a digressão no texto acadêmico.

A priori, se efetuará a análise dos pilares histórico-jurídicos que propiciaram o surgimento e o desenvolvimento dos Direitos Humanos nos âmbitos internacionais e supranacionais por meio do método dialéticohistórico para fornecer o supedâneo necessário a compreender a incidência destes no ordenamento brasileiro.

No tópico seguinte, será tratado o crivo realizado pelo ordenamento brasileiro ao integralizar os tratados internacionais sobre direitos humanos, progredindo para isso através da processualística concernente à formação dos Tratados Internacionais e a sua inclusão ao ordenamento jurídico brasileiro.

Ao fim, será verificada a consubstanciação dos finos vetores principiológicos e axiológicos fundamentais à Ciência dos Direitos Humanos às relações, diretrizes e matrizes curriculares dos cursos das faculdades particulares de Anápolis.

Portanto, ao contemplar a matéria, o pesquisador comporá a análise sob a vênia relação entre a ciência, a filosofia, a religião e o direito, de modo a entender o vínculo entre a carga humanística no bojo de disciplinas que integram o cerne do ensino superior e o indivíduo.

A pesquisa seguirá os estágios de investigação, de exame e de síntese nas fontes normativas e legislativas, bem como em dispositivos jurisprudenciais prolatados pelos principais tribunais brasílicos sem, entretanto, esquecer-se dos pilares responsáveis pelo arcabouço doutrinário, jurídico, histórico, político e social tangentes ao tema em comento.

\section{Surgimento dos Direitos Humanos}

A constituição inglesa do século XIII, onde, foram restringidos os poderes absolutos do monarca, havendo uma consequente valorização dos barões e prelados ingleses, desde então, a Inglaterra, vem sendo apontada como a precursora dos Direitos Humanos.

Mas foi a América do Norte, quem criou em 12 de janeiro de 1776, uma lei específica para salvaguardar os direitos dos homens, a chamada Declaração de Direitos. A partir de então, o tema, começou a disseminar pelos continentes.

Em 1789 a França, se baseando na lei criada pela América do Norte, e devido a revolução francesa, aderiu também pela proteção dos direitos do homem, quando na Assembleia Nacional Francesa, foi a provada a "Declaração dos Direitos do Homem e do Cidadão". 
Surge, com o fim da Segunda Guerra Mundial, a ideia de uma nova Declaração, a Organização das Nações Unidas, e sua terceira Assembleia Geral, aprova o documento intitulado de Declaração Universal dos Direitos Humanos. Assim, a ONU, evidenciou, que a existência de tais direitos são inerentes a pessoa humana, ou seja, não podem ser restringidos ou retirados, por nenhum indivíduo, entidade, governo ou Estado.

O próprio preambulo da Declaração Universal de Direitos Humanos, demonstra que esta, derivou-se do impacto das atrocidades cometidas durante a Segunda Guerra Mundial. Contudo a revelação dessas ações, foi feita a princípio omitindo tudo o que se referia à União Soviética, e os diversos atos cometidos pelas potências ocidentais durante a guerra.

Em 1990, a Europa deu um importante passo, nesse âmbito, com a assinatura da Carta de Paris, onde, foram criadas normas mais precisas sobre os direitos do homem e das minorias, mostrando para o restante do mundo que busca pela seguridade dos direitos do homem, não deve cessar.

\section{Diferença entre Direitos Humanos e Direitos Fundamentais}

Ouve-se muito falar em "direitos humanos" e "direitos fundamentais" porém se faz necessário distingui-los, vez que possuem interesses diferentes, para Charles Marlik, em 1947, relator da Comissão de Direitos Humanos (CES-ONU), afirmava que:

A expressão 'Direitos do Homem' refere-se obviamente ao homem, e com 'direitos' só se pode designar aquilo que pertence à essência do homem, que não é puramente acidental, que não surge e desaparece com a mudança dos tempos, da moda, do estilo ou do sistema; deve ser algo que pertence ao homem como tal.

Logo, para Marlik, os direitos do homem, não devem sofrer alteração pelo decurso do tempo, uma vez que esses direitos visam assegurar a essência do ser, que lhe é comum a todos os seres. Afirmação essa que contrapõe a diversidade cultural do homem, defendendo que as necessidades de resguardar os direitos do homem, devem sim sofrer alterações de acordo com sua cultura, vedando a afirmação de que todo homem deve ter a mesma proteção, pois cada cultura possui suas particularidades, o que tornaria essa forma de proteção ineficaz, devendo portanto resguardar o homem como um todo, mas resguardando em sua cultura.

O posicionamento de Sarlet, distingue as duas terminologias por esferas, sendo uma utilizada na esfera constitucional e outra na esfera internacional. Já sob o aspecto formal e material, Jane Reis Gonçalves (2006, p.77), explica da seguinte forma:

Do ponto de vista formal, direitos fundamentais são aqueles que a ordem constitucional qualifica expressamente como tais. Já do ponto de vista material, são direitos fundamentais aqueles direitos que ostentam maior importância, ou seja, os direitos que devem ser reconhecidos por qualquer Constituição legítima. Em outros termos, a fundamentalidade em sentido material está ligada à essencialidade do direito para implementação da dignidade humana. Essa noção é relevante pois, no plano constitucional, presta-se como critério para identificar direitos fundamentais fora do catálogo. 
Desta forma, Jane Reis, mostra-se favorável ao posicionamento de Sarlet, pois ambos afirmam em sua obras, que os direitos fundamentais são aqueles defendidos pela constituição.

Contudo, pode-se afirmar, que, em síntese, os Direitos Fundamentais, são os previstos na Constituição de modo geral, já os Direitos Humanos, são a totalidade de direitos que reservam a existência da pessoa humana em todo o mundo, e servem como base para que os Estados possam criar em incorporar seus direitos fundamentais. Logo, os Direitos Fundamentais, são derivados de uma esfera maior e completa que são os Direitos Humanos.

\section{Evolução dos Direitos Humanos no Brasil}

Tem-se como verdade, que, o que rege um país é a Carta Magna que este possui, e desta forma, não seria diferente com o Brasil. A primeira Constituição brasileira deu-se em 1824, pelo Imperador D. Pedro II, que tratou dos direitos Humanos de forma genérica, referindo-se apenas a Declaração dos Direitos do Homem e do Cidadão, de 1789, como bem trata Ives Filho em sua obra.

Quando instituída a República, criou-se uma nova Constituição, em 1891, e esta trouxe uma significativa mudança no cenário político, transformando o Estado Unitário, em Estado Federativo, mantiveram-se as mesmas considerações acerca dos Direitos Humanos, porém, até então não haviam mecanismos que pudessem efetivar esses direitos.

O pensamento dos constitucionalistas começam a mudar, no governo de Getúlio Vargas, com a nova Constituição de 1934, que de forma mais efetiva começam a surgir os primeiros direitos claramente delineados, de valorização do homem, aduzindo garantias como direito de voto para as mulheres, normas trabalhistas, instituindo o salário mínimo, estabelecendo uma jornada de trabalho de oito horas diárias, vedando o trabalho infantil, etc, entre tantos outros benefícios.

Neste sentido, a professora Ana Cláudia Scarquette (2006, p.273) afirma que:

O dilatado grau de intervencionismo econômico e social, que a Constituição de 1934 adotou, repercutiu no alargamento da competência da União Federal, para atender às novas dimensões do Estado, e esse processo de dilatação da competência federal acarretou a correspondente redução da autonomia do Estado-membro.

Conforme o pensamento da professora Scarquette, esta nova posição do Estado, trouxe uma grande intervenção econômica quando reconhece direitos trabalhistas e social, quando surgem os primeiros indícios de igualdade entre os homens quando permite o voto feminino.

Em 1937, surge uma nova Constituição promulgada por Getúlio Vargas, que extinguiu o Estado Federativo, e instituiu novamente o Estado Unitário, assim com as mudanças no cenário politico, o país passa por um período de grande conturbação politica e social, mas é somente em 1967 com a volta do Federalismo, e se institui uma nova Constituição que ampliam os poderes da União, assim o rol de direitos e garantias foi ampliado, e incluiu-se a proteção aos direitos políticos. 
Surge uma nova crise política da segunda metade de 1968, que derivou a promulgação do Ato Institucional no 5 , foi totalmente extinta a federação no Brasil durante aquela época. Mas em outubro de 1988, é promulgada a atual Constituição Brasileira, e nesta é contemplada com um rol mais extenso de direitos e garantias fundamentais, aduzindo já em seu primeiro artigo tais garantias:

Art. 1० A República Federativa do Brasil, formada pela união indissolúvel dos Estados e Municípios e do Distrito Federal, constitui-se em Estado Democrático de Direito e tem como fundamentos:

I - a soberania;

II - a cidadania;

III - a dignidade da pessoa humana;

IV - os valores sociais do trabalho e da livre iniciativa;

V- o pluralismo político.

A atual constituição destina ainda um capítulo próprio para as garantias fundamentais de seus cidadãos, reforçando a ideia de que todos são iguais perante a lei, como traz o caput do artigo $5^{\circ}$ da Carta Magna:

Art. $5^{\circ}$ Todos são iguais perante a lei, sem distinção de qualquer natureza, garantindo-se aos brasileiros e aos estrangeiros residentes no País a inviolabilidade do direito à vida, à liberdade, à igualdade, à segurança e à propriedade, nos termos seguintes:

Desta forma, esta mostra-se como a Constituição mais democrática que já houve na história deste país, e também aquela que melhor reconheceu os direitos inerentes a dignidade da pessoa humana.

\section{Importantes tratados internacionais que o Brasil faz parte}

Antônio Augusto ressalta que o Brasil, desde a promulgação da Constituição de 1988, vem dando destaque para o assunto, e mostra-se cada vez mais empenhado na adoção de medidas em prol da agregação de tratados internacionais voltados à proteção dos Direitos Humanos. Assim, o país já é signatário dos mais importantes tratados internacionais de Direitos Humanos, tanto pela Organização das Nações Unidas (ONU), como pela Organização dos Estados Americanos (OEA). Pode-se destacar, dentre eles, o Pacto Internacional dos Direitos Civis e Políticos, o Pacto Internacional dos Direitos Econômicos, Sociais e Culturais, a Convenção Contra a Tortura e Outros.

Vale salientar que a promulgação da Constituição de 1988, foi imprescindível para que esses tratados fossem ratificados pelo Brasil, pois esta nova Carta Magna, reconhece direitos que antes nunca haviam sido valorizados em constituições anteriores.

No âmbito interamericano, o Brasil também é signatário em praticamente todos os tratados existentes, como a Convenção Americana sobre Direitos Humanos (1969), o Protocolo Adicional à Convenção Americana sobre Direitos Humanos em Matéria de Direitos Econômicos, Sociais e Culturais (1988), o Protocolo à Convenção Americana sobre Direitos Humanos Referente à Abolição da Pena de Morte (1990), entre outros.

Evidencia-se que o Brasil atuou ativamente nos trabalhos preparatórios da Convenção Americana, e, na conferência de 1969 de San José da Costa Rica, onde demonstrou apoio na sua adoção de forma integral, inclusive 
quanto a suas cláusulas facultativas, como a do art. 62, sobre o recebimento pelos Estados-partes da competência contenciosa da Corte Interamericana.

Porém, em contrapartida, desde a ratificação do Pacto Internacional dos Direitos Civis e Políticos, no ano de 1992, o Brasil vem deixando a desejar em submeter-se à jurisdição do Comitê de Direitos Humanos das Nações Unidas, embora o Plano Nacional de Direitos Humanos(PNDH) comprometa o País.

Desde a promulgação da atual Constituição, o Brasil continua a luta em defesa destes direitos, ratificando os tratados internacionais sobre este tema, e ainda demonstra de forma executiva uma preocupação em como esses direitos vem sendo exercidos fáticamente no país, quando reconhece a jurisdição de órgãos de monitoramento pertinentes, e quando atua de maneira transparente dialogando com órgãos internacionais competentes.

Porém mostra-se indispensável apontar que o país ainda, que tenha evoluído quanto ao tema, prevê, um longo caminho até o aperfeiçoamento de sua efetiva prestação à segurança aos direitos inerentes a pessoa humana, levando-se em consideração os casos em que o Brasil foi levado como réu à Comissão Interamericana de Direitos Humanos.

Norberto Bobbio aduz e sua obra, a importância de citar alguns destes casos como por exemplo, a Casa de Detenção Mário Alves, comumente conhecida como "Urso Branco" no estado de Rondônia; outro caso levado a Corte Interamericana é o caso conhecido como Damião Ximenes Lopes envolvendo o Sistema Único de Saúde e uma casa de saúde da cidade de Guararapes; em 1995 surge outra denúncia desta vez o caso do menino Jailton Neri da Fonseca ,envolvendo policiais, na cidade do Rio de Janeiro. Entre tantos outros casos, o último, foi no final do ano 2000, uma denúncia contra a FEBEM, mas pode-se dizer que o país vem em uma incessante tentativa de reverter este quadro.

Nesta esteira, é crucial lembrar o posicionamento de Flavia Piovesan (1996, p.112):

Esta mudança na agenda internacional brasileira, consequência do processo de democratização iniciado no Brasil a partir de 1985, contribuiu definitivamente para uma nova inserção do País no cenário internacional, e isso foi fruto dos novos valores democráticos que demarcaram o fim de um período de autoritarismo em que se encontrava a Nação.

Como bem expressa o posicionamento de Piovesan, os Direitos Humanos, trouxe benefícios ao país que vão além da mera proteção, mas também serviu de escopo para o a inserção do país no cenário internacional, trazendo ao país não só uma visibilidade sob uma ótica de crescimento e evolução, mas também podendo ser reconhecido como um grande potencial de desenvolvimento.

\section{A formação dos Tratados Internacionais de Direitos Humanos}

Em momento anterior ao enfoque puramente normativo, imperiosa se demonstra a abordagem, embora sucinta, sobre os contornos fundantes dos objetos jurídicos dos tratados internacionais, vez que estes pilares fundamentais da doutrina são intrínsecos à compreensão do instituto. 
Nos dizeres sempre expressivos da eminente professora Flávia Piovesan (2013, p. 234) in Direitos Humanos e o Direito Constitucional Internacional, pode-se compreender a incidência do vetor principio lógico do pacta sunt servanda ao passo que são contratos cogentes e vinculantes ao constituir fonte originária de deveres e direitos em âmbito internacional, vejamos:

Começa-se por afirmar que os tratados internacionais, enquanto acordos internacionais juridicamente obrigatórios e vinculantes (pacta sunt servanda), constituem hoje a principal fonte de obrigação do Direito Internacional. [...] Foi com o crescente positivismo internacional que os tratados se tornaram a fonte maior de obrigação no plano internacional, papel até então reservado ao costume internacional. Tal como no âmbito interno, em virtude do movimento do Pós-Positivismo, os princípios gerais de direito passam a ganhar cada vez maior relevância como fonte do Direito Internacional na ordem contemporânea.

Sob este enfoque, foi possível coligir que a marcha positivista contribuiu para a integração dos tratados ao direito internacional como a fonte por excelência, por tal razão a integralização dos diplomas internacionais aos sistemas jurídicos pátrios se constituiu como natural seguimento.

Assim, o tratado será, na visão de Louis Henkin (2002, p. 197) in International Law: a student introdution, o termo a ser utilizado para definir a congruência de vontades em âmbito internacional quando obrigatório e realizado pelos sujeitos do Direito Internacional, a saber:

O termo 'tratado' é geralmente usado para se referir aos acordos obrigatórios celebrados entre sujeitos de Direito Internacional, que são regulados pelo Direito Internacional. Além do termo 'tratado', diversas outras denominações são usadas para se referir aos acordos internacionais. As mais comuns são Convenção, Pacto, Protocolo, Carta, Convênio, como também Tratado ou Acordo Internacional. Alguns termos são usados para denotar solenidade (por exemplo, Pacto ou Carta) ou a natureza suplementar do acordo (Protocolo).

Por esta lição é certa a assertiva de que se trata de que "tratado" é um termo genérico, usado para incluir as convenções, os acordos, os protocolos e a troca de instrumentos, pois o Direito Internacional não distingue os acordos identificados como tratados, dos outros acordos. O termo escolhido para se referir a um acordo não é em si mesmo importante e não apresenta maior consequência jurídica.

Ainda na lição de Flávia Piovesan (2013) compreende-se que os acordos internacionais não são marcados essencialmente pelo ineditismo normativo, pois revelam-se por vezes como a mera codificação e consagração de regras preexistentes, balizadas pelo costume internacional, ou, ainda, no exemplo da atualização destes.

Tem-se, desta forma, a necessidade de tutelar e regrar a liturgia concernente à gênese dos Tratados Internacionais pôde ser vislumbrada na elucubração da Convenção de Viena, finalizada em 1969, ao ser estampada como a Lei dos Tratados, como bem diz Flávia Piovesan (2013, p. 235):

A necessidade de disciplinar e regular o processo de formação dos tratados internacionais resultou na elaboração da Convenção de Viena, concluída em 1969, que teve por finalidade servir como a Lei dos Tratados. Contudo, limitou-se aos tratados celebrados entre os Estados, não envolvendo aqueles dos quais participam organizações internacionais. 
Ante o exposto, tem-se por consequência que o termo "tratado" significa um acordo internacional concluído entre Estados, na forma escrita e regulado pelo Direito Internacional, e por igual fundamento, somente será aplicável e exigível dos Estados membros.

Importante destacar que a assinatura do documento vincula o Estado Membro, pois somente pode ser concluído quando existe a plenitude no consentimento, e em razão disso não poderá resultar em descumprimento, salvo se contiver vício de consentimento por hipótese de ameaça ou pelo uso da força, conforme dispõe a Convenção de Viena:

Artigo 26. Pacta sunt servanda. Todo tratado em vigor obriga as partes e deve ser cumprido por elas de boa fé

[...]

Artigo 57. Suspensão da Execução de um Tratado em Virtude de suas Disposições ou pelo Consentimento das Partes. A execução de um tratado em relação a todas as partes ou a uma parte determinada pode ser suspensa:

a) de conformidade com as disposições do tratado; ou

b) a qualquer momento, pelo consentimento de todas as partes, após consulta com os outros Estados contratantes.

Desta maneira, oportuna se torna a menção que embora a Convenção de Viena tenha sido concluída em 23

de maio de 1969, e assinalada pela República Federativa do Brasil na mesma data, somente foi ratificada em 25 de setembro de 2009 por meio do decreto 7.030/2009.

Assim, é de se evocar a preleção dedicada pela professora Flávia Piovesan (2013, p. 236) in Direitos Humanos e o Direito Constitucional Internacional ao inferir que os tratados internacionais podem ser formulados com fixação de ressalvas, traz-se à baila:

Em geral, os tratados permitem sejam formuladas reservas, o que pode contribuir para a adesão de maior número de Estados. Nos termos da Convenção de Viena, as reservas constituem "uma declaração unilateral feita pelo Estado, quando da assinatura, ratificação, acessão, adesão ou aprovação de um tratado, com o propósito de excluir ou modificar o efeito jurídico de certas previsões do tratado, quando de sua aplicação naquele Estado". Entretanto, são inadmissíveis as reservas que se mostrem incompatíveis com o objeto e propósito do tratado, nos termos do art. 19 da Convenção.

Por esta valiosa lição, é compreensível a viabilidade de restringir o alcance dos efeitos e das consequências advindas dos Tratados Internacionais assinalados por um Estado, desde que atenda às regras de limitação estampadas no bojo da Convenção de Viena, a saber:

Artigo 19. Formulação de Reservas. Um Estado pode, ao assinar, ratificar, aceitar ou aprovar um tratado, ou a ele aderir, formular uma reserva, a não ser que:

a) a reserva seja proibida pelo tratado;

b) o tratado disponha que só possam ser formuladas determinadas reservas, entre as quais não figure a reserva em questão; ou

c) nos casos não previstos nas alíneas a e b, a reserva seja incompatível com o objeto e a finalidade do tratado. 
Nos termos da sublime norma, são necessários alguns requisitos para autorizar a fixação de limites a tratado internacional desde que a não seja defesa a reserva pelo próprio documento, atenda às hipóteses de reservas dispostas no cerne do tratado, ou ainda, caso macule a finalidade e o objeto sobre o qual versa o acordo.

Neste sentido, Henkin (2002) clarifica a leitura ao destilar que as reservas ampliam a participação de Estados, que sem as quais tornariam dificultada a adesão. Todavia, destaca a utilização destes elementos por certos entes para enfraquecer, substancialmente, as consequências almejadas pelas Convenções, ao tornar incompatível seu objeto e propósito.

Desbastados, os pontos atinentes aos procedimentos que sustentam a regular formação de um Tratado Internacional sob o crivo e baliza da Convenção de Viena de 1969, o estágio seguinte cuidará da integralização e da eficácia conferida aos Tratados Internacionais sobre Direitos Humanos no ordenamento jurídico brasileiro.

\section{A inclusão no ordenamento jurídico brasileiro de Tratados Internacionais de Direitos Humanos}

Antes de nos fixarmos na íntegra dos diplomas normativos derivados de composições diplomáticas internacionais é interessante compreender o real sentido dos dizeres contidos no bojo do artigo $5^{\circ}$, parágrafos $2^{\circ}$ e $3^{\circ}$ da Lei Suprema da República Brasileira, a saber:

Art. $5^{\circ}$ Todos são iguais perante a lei, sem distinção de qualquer natureza, garantindo-se aos brasileiros e aos estrangeiros residentes no País a inviolabilidade do direito à vida, à liberdade, à igualdade, à segurança e à propriedade, nos termos seguintes:

[...]

$\$ 2^{\circ}$ Os direitos e garantias expressos nesta Constituição não excluem outros decorrentes do regime e dos princípios por ela adotados, ou dos tratados internacionais em que a República Federativa do Brasil seja parte.

$\$ 3^{\circ}$ Os tratados e convenções internacionais sobre direitos humanos que forem aprovados, em cada Casa do Congresso Nacional, em dois turnos, por três quintos dos votos dos respectivos membros, serão equivalentes às emendas constitucionais.

A importância dos tratados internacionais sobre direitos humanos levou o legislador constituinte revisor adicionar ao rol de direitos e garantias fundamentais inerentes ao indivíduo no fulcro à preservação da Dignidade da Pessoa Humana, a possibilidade do aumento deste leque em face da adoção pelo ordenamento brasileiro de Convenções e de Tratados Internacionais.

É imperiosa a atenção que a visão do constituinte de 1988, embora vanguardista, foi cautelosa ao definir regras para incorporação de Tratados Internacionais, pois versasse sobre direitos humanos ou não, era muito tradicional em face dos artigos 49, inciso I combinado ao 84, inciso VIII, a saber:

Art. 49. É da competência exclusiva do Congresso Nacional:

I - resolver definitivamente sobre tratados, acordos ou atos internacionais que acarretem encargos ou compromissos gravosos ao patrimônio nacional;

[...]

Art. 84. Compete privativamente ao Presidente da República:

$[\ldots]$ 
VIII - celebrar tratados, convenções e atos internacionais, sujeitos a referendo do Congresso Nacional;

Por estes dispositivos foi possível coligir, que o Presidente da República ficaria com a autoridade de celebrar os atos internacionais sobre direitos humanos ao representar o Estado Brasileiro, e este acordo internacional não produziria efeitos na órbita interna e na órbita internacional de forma imediata.

Restaria, portanto, ser submetido ao crivo do Congresso Nacional para após deliberação e aprovação, e por meio de um Decreto Legislativo retornava ao Chefe do Poder Executivo Federal para a futura promulgação sob a forma de Decreto Presidencial.

Nesse sentido, é compreensível que o status dos diplomas normativos sobre direitos humanos, ou não, aprovados segundo esta liturgia possuíam a mesma hierarquia de normas ordinárias federais, ou leis infraconstitucionais, este entendimento sofreu severas críticas pela doutrina brasileira e somente materialmente alterado pelo advento da 45a Emenda à Constituição da República Federativa do Brasil, ocorrida em 2004, ao assegurar aos acordos internacionais firmados pelo Estado Brasileiro o status de norma constitucional quando submetidos ao rito dispensado às Emendas à Constituição, evoca-se o presente:

Art. 5०. [...]

$\$ 3^{\circ}$ Os tratados e convenções internacionais sobre direitos humanos que forem aprovados, em cada Casa do Congresso Nacional, em dois turnos, por três quintos dos votos dos respectivos membros, serão equivalentes às emendas constitucionais.

Esta inovação normativa permitiu ao parlamento brasileiro constituir material e formalmente a natureza jurídica constitucional aos tratados internacionais celebrados pela República Federativa do Brasil, caso o Congresso Nacional assim julgue.

Respeitável menção se faz ao Decreto 6.949 de 25 de agosto de 2009 que promulgou, integralizou e constitucionalizou no sistema jurídico-forense brasileiro o primeiro dos Tratados Internacionais sobre Direitos Humanos, dotando a hierarquia de norma constitucional à Convenção Internacional sobre os Direitos das Pessoas com Deficiência, de 30 de março de 2007, traz-se à baila o preâmbulo do referido decreto:

O PRESIDENTE DA REPÚBLICA, no uso da atribuição que lhe confere o art. 84, inciso IV, da Constituição, e

Considerando que o Congresso Nacional aprovou, por meio do Decreto Legislativo no 186, de 9 de julho de 2008, conforme o procedimento do $\$ 3^{\circ}$ do art. $5^{\circ}$ da Constituição, a Convenção sobre os Direitos das Pessoas com Deficiência e seu Protocolo Facultativo, assinados em Nova York, em 30 de março de 2007;

Considerando que o Governo brasileiro depositou o instrumento de ratificação dos referidos atos junto ao Secretário-Geral das Nações Unidas em 1º de agosto de 2008;

Considerando que os atos internacionais em apreço entraram em vigor para o Brasil, no plano jurídico externo, em 31 de agosto de 2008;

Como se percebe, restou aprovado o venerado Tratado Internacional sob a batuta e crivo da liturgia legada pelo parágrafo $3^{\circ}$ do artigo $5^{\circ}$ da Bíblia Política Brasileira que determina a aprovação de $3 / 5$ (três quintos) de cada casa do Congresso Nacional em dois turnos em cada uma delas, adquirindo, assim, a carga jurídica de norma, formal e materialmente, constitucional. 
Desta maneira, é inafastável a observância ao conteúdo vinculado pela parte dispositiva do Decreto presidencial em tela que testifica a obrigatoriedade da apreciação pelo Congresso Nacional de atos e compromissos internacionais firmados pelo Chefe do Poder Executivo que possam incorrer em obrigações e direitos pelo Estado Brasileiro, evoca-se o disposto:

Art. 1º A Convenção sobre os Direitos das Pessoas com Deficiência e seu Protocolo Facultativo, apensos por cópia ao presente Decreto, serão executados e cumpridos tão inteiramente como neles se contém.

Art. 20 São sujeitos à aprovação do Congresso Nacional quaisquer atos que possam resultar em revisão dos referidos diplomas internacionais ou que acarretem encargos ou compromissos gravosos ao patrimônio nacional, nos termos do art. 49, inciso I, da Constituição.

Neste sentido, imperiosa se torna a atenção à situação normativa-hierárquica dos Tratados Internacionais sobre Direitos Humanos que não foram submetidos ao rito disciplinado pela Emenda 45 de 2004, que somente pôde ser pacificada pelos Tribunais Superiores.

Somente nos julgamentos do Habeas Corpus 87.585 do Tocantins e do Recurso Extraordinário 466.343 de São Paulo pelo Supremo Tribunal Federal foi ventilada a Teoria da Supralegalidade dos Tratados de Direitos Humanos não perpassados à liturgia da Emenda Constitucional 45 de 2004.

De relatoria do Ministro Cezar Peluso, o julgamento Recurso Extraordinário 466.343 de São Paulo rompeu com toda a sistemática até então ao considerar ilícita a qualquer modalidade de prisão civil de depositário infiel, segue a ementa:

EMENTA: PRISÃO CIVIL. Depósito. Depositário infiel. Alienação fiduciária. Decretação da medida coercitiva. Inadmissibilidade absoluta. Insubsistência da previsão constitucional e das normas subalternas. Interpretação do art. $5^{\circ}$, inc. LXVII e $\$ \$ 1^{\circ}, 2^{\circ}$ e $3^{\circ}$, da CF, à luz do art. 7o, $\$ 7$, da Convenção Americana de Direitos Humanos (Pacto de San José da Costa Rica). Recurso improvido. Julgamento conjunto do RE no 349.703 e dos HCs no 87.585 e no 92.566. É ilícita a prisão civil de depositário infiel, qualquer que seja a modalidade do depósito. (RE 466343, Relator(a): Min. CEZAR PELUSO, Tribunal Pleno, julgado em 03/12/2008, DJe-104 DIVULG 04-06-2009 PUBLIC 05-06-2009 EMENT VOL-02363-06 PP-01106 RTJ VOL00210-02 PP-00745 RDECTRAB v. 17, n. 186, 2010, p. 29-165)

Assim de igual maneira foi inequívoca a posição do Excelso Pretório ao reconhecer a impossibilidade da prisão civil do Depositário Infiel em face dos Tratados Internacionais de Direitos Humanos ao dotar aos Tratados Internacionais de Direitos Humanos não submetidos ao rito concernente ao disposto no parágrafo $4^{\circ}$ do artigo $5^{\circ}$ da Magna Carta patamar hierárquico-normativo sui generis à pirâmide preconizada por Kelsen.

Seguindo tal inteligência, é inequívoca a submissão dos referentes pactos diplomáticos às balizas axiomáticas e fundantes da Lei Maior, depreende-se desta maneira a perene hipótese de inconstitucionalidade de Tratado mesmo que devidamente subscrito pelo Estado signatário, quando contrariar ideais expressos na norma fundamental.

Elementar será a compreensão do rigor da correspondência princípio lógica entre as normas em locais distintos de uma mesma hierarquia para sistemática do ordenamento, figurando a Convenção Americana sobre 
Direitos Humanos de 1969 em lógica e mandamento superior à legislação infraconstitucional-interna devendo estes serem congruentes em seus desígnios, concepções e perspectivas.

Ademais, convém o cotejamento à ementa do acórdão do paradigmático julgamento do Habeas Corpus 87.585 do Tocantins, em que o Ministro-Relator Marco Aurélio, limitou a eficácia da norma infraconstitucional presente no Código do Processo Civil de 1973 e do Códex Civil de 2002 vez que contrariou o previsto no bojo da Convenção Interamericana de Direitos Civis de 1969, isto posto, evoca-se o presente:

DEPOSITÁRIO INFIEL - PRISÃO. A subscrição pelo Brasil do Pacto de São José da Costa Rica, limitando a prisão civil por dívida ao descumprimento inescusável de prestação alimentícia, implicou a derrogação das normas estritamente legais referentes à prisão do depositário infiel. (HC 87585, Relator(a): Min. MARCO AURÉLIO, Tribunal Pleno, julgado em 03/12/2008, DJe-1 18 DIVULG 25-06-2009 PUBLIC 26-06-2009 EMENT VOL-02366-02 PP-00237)

Tem-se por força da normatividade constante nos Tratados Internacionais de Direitos Humanos aderidos pelo Estado Brasileiro à obrigatoriedade da correspondência de finalidade pelos demais dispositivos, sob pena de incorrer em mácula e, portanto, sua inaplicabilidade no plano real.

\section{Aprofundamentos da questão ante a pesquisa de campo}

A presente pesquisa foi realizada com 03 (três) coordenadores pedagógicos de Instituições de Ensino Superior da Cidade de Anápolis Goiás, para definição de cada indivíduo foram formuladas perguntas sobre a prática educacional do Coordenador Pedagógico da Instituição de ensino superior sobre a importância dos Direitos Humanos nas Faculdades. O período da pesquisa foi de fevereiro de 2015 a julho de 2016.

\section{Questionário de Pesquisa para Coordenadores}

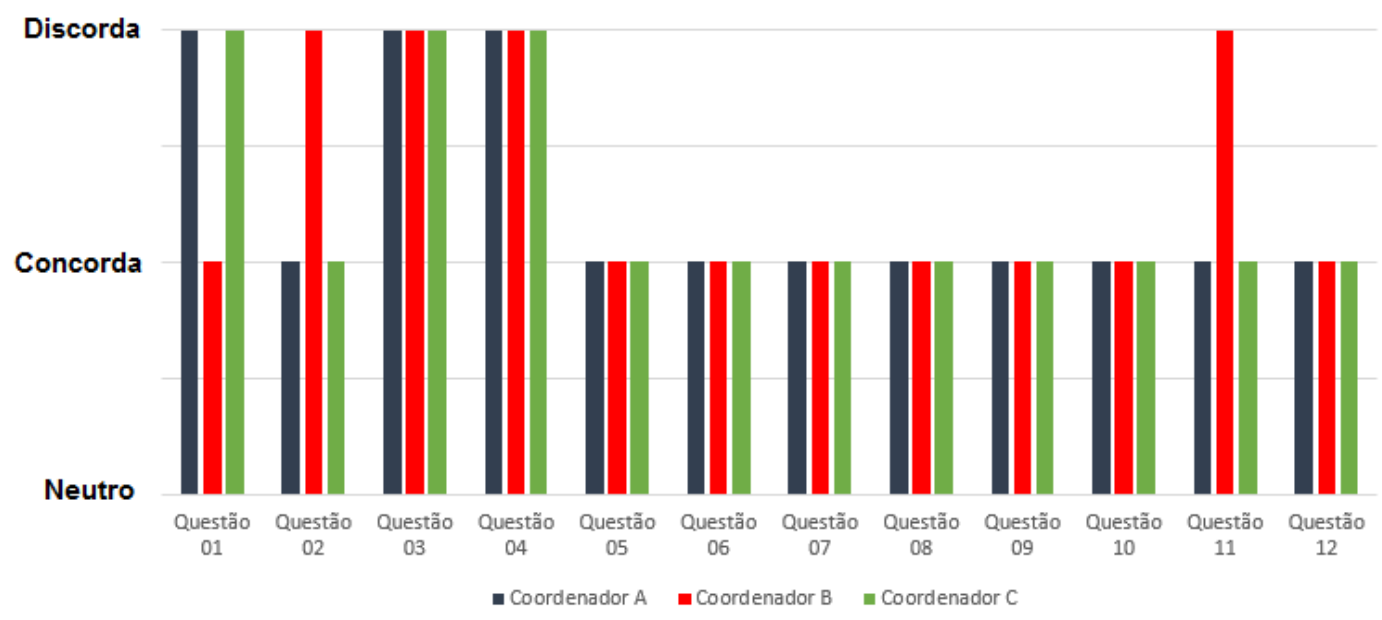

As instituições que participaram da referida pesquisa, neste, representadas por seus coordenadores, mostraram-se receptivas ao tema, e interessadas no estudo desenvolvido, reconhecendo assim, na prática que o vol.11, nº. 01, Rio de Janeiro, 2018. pp. 529-547 
estudo dos Direitos Humanos, é de suma importância na formação de profissionais, que atuam nos mais diversos ramos do mercado de trabalho.

Desta maneira, ante as respostas apresentadas foi possível depreender a comum preocupação de todos os agentes responsáveis pela delimitação e coordenação das matrizes pedagógicas dos cursos de graduação das Instituições de Ensino Superior objeto da pesquisa em promover e em viabilizar ao corpo docente a constante qualificação para a formação contínua, pois a nobre tarefa da transmissão do saber exige a atenção ao fluxo do tempo e da sociedade, que se traduzem no cotejamento e na elevação da proteção aos pilares dos direitos humanos na sociedade e para o indivíduo como se asseverará nos tópicos seguintes.

\section{Como as faculdades vêm abordando este tema}

No presente ponto da análise, o vislumbre acadêmico pode ser mais bem compreendido pelas Diretrizes Curriculares do Curso de Direito ao constituir as concepções didático-pedagógicos na formação dos acadêmicos e futuros operadores do direito, assim, traz-se à baila:

As diretrizes curriculares têm em mira fornecer as linhas gerais para os cursos jurídicos estruturarem seus projetos pedagógicos de forma autônoma e criativa, segundo suas vocações, demandas sociais e mercado de trabalho, objetivando a formação de recursos humanos com elevado preparo intelectual e aptos para o exercício técnico e profissional do Direito. [...]

Elas não constituem prescrições fechadas e imutáveis, mas parâmetros a partir dos quais os cursos criarão seus currículos em definitiva ruptura com a concepção de que são compostos de uma extensa e variada relação de disciplinas e conteúdos como saberes justapostos ou superpostos e que não passam de repetição do já pensado (MEC, 2000).

Ante o exposto, é possível depreender a preocupação do poder público ao determinar a inclusão às balizas dos cursos de graduação a formação humanística dos profissionais e egressos do ensino superior como elemento integrador da doutrina técnica-jurídica, a saber:

O perfil desejado do formando de Direito repousa em uma sólida formação geral e humanística, com capacidade de análise e articulação de conceitos e argumentos, de interpretação e valoração dos fenômenos jurídico-sociais, aliada a uma postura reflexiva e visão crítica que fomente a capacidade de trabalho em equipe, favoreça a aptidão para a aprendizagem autônoma e dinâmica, além da qualificação para a vida, o trabalho e o desenvolvimento da cidadania (MEC, 2000).

Desta maneira, percebe-se que a formação acadêmica dispensada pelos cursos superiores, pois exigem que o discente agregue sólida constituição cultural-humanista e jurídica para a análise factual-normativa dos célebres institutos jurídicos.

Este entendimento corrobora para a edificação de um corpo discente e profissional capaz de desenvolver robusta análise no mundo profissional e pessoal, pautados nos alicerces da dignidade da pessoa humana e da democracia. 


\section{A importância dos Direitos Humanos nos cursos de graduação}

É imperiosa a atenção em distinguir que as verdades de fé estão no campo da autoridade de Deus, as verdades da filosofia estão no campo das verdades da razão, e as verdades científicas estão no campo das verdades experimentais: são três campos distintos, mas não opostos.

Como bem cotejado nos capítulos anteriores a doutrina humanista comporta a utilização de elementos socializadores da Cultura em Direitos Humanos, para disseminar nas práticas e relações sociais a busca de meios a capacitar os sujeitos, em âmbito individual e coletivo, para salvaguardar seus direitos ao defender e promover movimentos culturais, nas palavras de Michael Apple (1998, p. 65) in Política cultura e Educação:

$\mathrm{O}$ que nos une, não pode ignorar o que nos separa. De igual modo, o que nos separa, não pode ignorar o que nos une. Caso contrário, estaremos reiterando uma concepção e uma prática abstratas de uma universalidade apenas discursiva; ou concepções e práticas concretas de particularidades fechadas e de pouco alcance para a superação ou minimização da desigualdade e da discriminação. A Cultura dos Direitos Humanos, sem dúvida, empreendeu um avanço considerável dos últimos anos 80 para cá, no que se refere a instrumentos normativos, expressando experiências de acordos interculturais. A construção de uma socialização pertinente dos Direitos Humanos implica relevar as conquistas de direitos já acumuladas considerando os processos de seu alargamento, ao longo da História, e refletindo sobre a perspectiva de novos alargamentos.

Ademais, é valoroso rememorar que os processos educativos $a b$ ovo não se demonstram preocupados na preservação e socialização do patrimônio cultural de uma pluralidade de segmentos, ao se dedicar a propagar e exaltar o determinado traço cultural europeu, cristão e caucasiano.

A acidez da crítica desenvolvida por Boaventura Santos (1998, p. 65) compreende que a concepção ocidental influi na negação à pluralidade de formas de conhecimento em levante a uma única forma de conhecimento, conclui a existência entre conhecimento-regulação e o conhecimento-emancipação, vejamos:

A concepção ocidental sobre as relações entre ignorância e conhecimento é uma sequência (sic) lógica (da ignorância para o conhecimento) e temporal (do passado=ignorância para o futuro=conhecimento), que o sociólogo refuta, distinguindo os dois tipos de conhecimento constitutivos do paradigma da modernidade ocidental: o conhecimento-regulação e o conhecimento-emancipação, que já abordamos anteriormente.

Assim, se a produção cultural é um produto de atuação coletiva, o seu reflexo e pormenorização tem sido feito às avessas e, portanto, reproduzindo os desígnios privados, vez que reflete aos holofotes a vertente de somente uma parcela da população.

Na lição de Rosa Maria Godoy Silveira (2009) in Educação em/para os direitos humanos: entre a universalidade e as particularidades, uma perspectiva histórica, o desenvolvimento histórico reinterpreta as produções sociais e culturais de determinados núcleos sociais sob a ótica de segmentos particulares da população para uma perspectiva privatista. 
Segundo Boaventura Santos (2006) é preciso cometer epistemicídio do paradigma ocidental, pois o cenário as relações desiguais de trocas culturais, ceifou toda uma pluralidade de conhecimentos de outras culturas através de atos derivados por genocídios de povos dominados pelos operadores de colonização e neocolonialismo.

Desta maneira, a ótica dos Direitos Humanos tem sido alterada desde a sua convolação representacional no pós 2a Guerra Mundial, vez que apresenta dimensões teóricas e práticas ao concebê-lo como um elemento de integração da cultura para a espécie humana em um horizonte universalizante, especado no fundamento de que se trata de direitos configurados como patrimônio comum da humanidade, como bem explica o Professor Pierre Bourdieu (2005, p. 110) in O poder simbólico:

Embora a Cultura de direitos tenha emergido no e construído o paradigma da modernidade ocidental, a Cultura de Direitos Humanos, tal como começa e se formaliza no século XX, já representa uma ultrapassagem da primeira. Seja quanto ao seu alcance sociocultural, seja também na abrangência das dimensões da vida humana contempladas.

Ainda nesta digressão, contempla-se que as territorialidades das culturas em específico não só determinam distintos modos de adoção e recepção dos Direitos Humanos, mas também, em muitas sociedades a refratividade a estas normas transindividuais.

Conquanto, a historicidade tangente aos direitos humanos emerja como um traço cultural específico, cabe apontarmos, mesmo que sinteticamente, o viés efetivamente universal que resultou da escalada dos direitos até a elaboração como perspectiva de socialização cultural.

Convém atentar que o meio acadêmico, queira-se ou não, acaba por socializar os indivíduos, de vários modos, e ante este profícuo devir as primeiras gerações, nossos mestres, assistem e auxiliam à construção e desconstrução de valores, definições, conceitos, signos, semânticas e ídolos que sustentaram as civilizações de outrora, como desvela o Professor Boaventura Santos (2006, p. 26) in A gramática do tempo:

Buscando compreender o processo constitutivo da modernidade, o autor o interpreta à luz de uma equação entre raízes e opções, que se combinaram na construção de uma concepção de identidade e de transformação social. A modernidade se erigiu como um período de opções, a exemplo da Reforma religiosa, da teoria racionalista do direito natural, do Iluminismo, do contrato social, do romantismo, que acabaram se convertendo em raízes que, por sua vez, abriram outras opções

Depreende-se a condução dos sistemas educacionais para as novas gerações como um objetivo fulcral de irromper com o estranhamento às diversidades sociais, políticas e raciais com o eixo na proteção e defesa do princípio supraconstitucional da dignidade da pessoa humana.

Essa reflexão é consistente ao campo da Ciência dos Direitos Humanos quando se vislumbra o movimento de inversão que se compreende o processo globalizatório sistêmico que deveria tender a solidificar o movimento de cidadania, age para desconstruir o indivíduo.

É por esta necessidade que a Educação em Direitos Humanos atua à emergência de propiciar meios à nova socialização cultural ao fornecer supedâneo para a incorporação de elementos moral-práticos, estético-expressivos e 
de natureza trans-canônicos, como se percebe na brilhante desmistificação promovida por George Yúdice (2004, p. 44):

\begin{abstract}
A imagem desestabilizadora, neste nível, é a de que vivemos num apartheid global sem entradas nem saídas, sendo necessária uma atitude cética contra variantes do universalismo que ignoram os desiguais; a identificação e estabelecimento de interfaces entre o específico e o geral, de modo a, mesmo havendo fronteiras mentais e espaciais, dispor-se de entradas e saídas; e o combate a toda pretensão de verdade absoluta. O que se propõe, finalmente, novas constelações de ideias, emoções, sentimentos de espanto e indignação, paixões. A construção de uma subjetividade que não desperdice experiências e plenifique as ações de novos sentidos. Realize o movimento das presenças (cânone) para as ausências (o que ficou oculto, excêntrico e marginal no passado), que construa as emergências (a irrupção do novo).
\end{abstract}

A busca na construção acadêmica do corpo discente ainda se especa em engendrar a socialização como a cultura de direitos, percorrendo as origens do pensamento crítico e lastreada pela torrente da universalidade dos Direitos Humanos.

Logo, as reflexões derivadas do princípio da universalidade dos Direitos Humanos e o seu cotejamento ante as particularidades próprias de cada segmento social e do próprio indivíduo viabilizarão a edificação de uma educação apta a socializar a Cultura para os Direitos Humanos ao aplicar uma visão abrangente às muitas trajetórias culturais até o presente.

Atenta a esses momentos histórico-culturais evidencia-se a congruência do conjunto de vetores, possibilidades e vedações em termos da socialização cultural almejada. Bem como, contempla-se a necessidade de construção de distintos conhecimentos e o fortalecimento da diversidade cultural através da educação.

\title{
CONSIDERAÇÕES FINAIS
}

A pesquisa foi consumada sob o fito de promover a desmistificação sobre as dimensões e as perspectivas da ciência dos direitos humanos no ensino superior das universidades particulares da cidade de Anápolis Goiás. E que deve sim recuperar as dimensões nas faculdades que não existe de acordo com a pesquisa.

Desta maneira, a análise acadêmica disposta no presente nos remeteu no mais reputável ensinamentos para materializar os princípios e os pilares jurídicos, bem como os fundamentos da sociologia que sustentam o arcabouço valorativo das bases da Ciência dos Direitos Humanos.

Nesta esteira, propiciou-se a compreensão sobre a força social e normativa da origem da Ciência dos Direitos Humanos no âmbito internacional e a digressão temporal do desenvolvimento e a afirmação das normas internacionais sobre direitos humanos como a edição da Declaração Universal dos Direitos Humanos.

Assim, conduziu-se no tópico seguinte a análise sobre a integralização dos documentos internacionais sobre direitos humanos para o ordenamento jurídico brasileiro bem como o cotejamento do tema ante a Lei dos Tratados ou a Convenção de Viena de 1969 e o questionamento sobre a supra legalidade dos Tratados Internacionais sobre Direitos Humanos não submetidos à liturgia de emenda à constituição. 
A disciplina de Direitos humanos pode, de igual maneira, fixar-se à análise de determinado fato ou acontecimento sob os limiares espacial e temporal, a esse fenômeno atribui-se a natureza e inclinação plurívoca e multifacetada da Égide Humanística.

Por fim, trabalhou-se a materialização dos máximos referenciais teórico-jurídico por meio de pesquisa de campo, realizada nos centros universitários particulares na cidade de Anápolis em Goiás, obtendo o resultado de que o ensino superior não está sendo trabalhados os eixos dos Direitos Humanos e consequentemente gerando uma sociedade sem cultura humanística.

Conclui-se que a pesquisa demonstrou que o ensino superior aliado aos eixos dos Direitos Humanos, pode ser a construção de uma sociedade justa e solidária e que deve convergir para o desenvolvimento do aprendizado social para a área de ciências social aplicadas.

\title{
DIMENSIONS AND PERSPECTIVES OF HUMAN RIGHTS: HIGHER EDUCATION OF THE PARTICULAR COLLEGES OF ANÁPOLIS GOIÁS
}

\begin{abstract}
This article is intended to trace the axiological and normative panoramas of Science of Human Rights and check the influence and importance of these rights in education in higher education in the universities of Anápolis Goiás. In the work dawn, it is justified to crushing the pillars that led to the emergence of the Science of Human rights through the dialectical-historical method. On this track, we seek the understanding of processualistic of the formation of international treaties on human rights and incorporation of the venerable documents to the Brazilian legal system. At the end, it embodied to the application of the fundamentals of human rights training of the student body in the midst of undergraduate courses through observation and field research in the higher education institution in the city of Annapolis, with proof and concern to consider of paramount importance in the continuous training of the teaching staff through the readback the Science of Human rights as backbone of the curriculum matrices. To achieve these goals we employed the dialectical-comparative methods through research, analysis and synthesis of regulatory and legislative texts, jurisprudential devices and doctrinal lectures, and application testing to verify the application of the conceptual vectors to undergraduate courses in institutions Teaching in the city of Anapolis Goiás.
\end{abstract}

Keywords: Human Rights; Higher education; Perspective and Applicability.

\section{REFERENCIAS}

APPLE, Michael. Política cultural e Educação. São Paulo: Cortez, 1998.

BOURDIEU, Pierre. O poder simbólico. Tradução de Fernando Thomaz. 8 ed. Rio de Janeiro: Bertrand Brasil, 2005. 
BRASIL. Constituição (1988). Constituição da República Federativa do Brasil: promulgada em 5 de outubro de 1988. Disponível em: < http://www.planalto.gov.br/ccivil_03/constituicao/constituicaocompilado.htm>. Acesso em: 17 de março de 2016.

\section{DECRETO 6949/2009}

Ministério da Educação e Cultura. Diretrizes Curriculares Do Curso De Direito de 13 de julho 2000. (Disponível em: http://portal.mec.gov.br/sesu/arquivos/pdf/dir_dire.pdf)

Supremo Tribunal Federal. Habeas Corpus 87585. Tribunal Pleno, Min. MARCO AURÉLIO, julgado em

03/12/2008, Diário da Justiça, Brasília, DF, 17 mar. 2009. (Disponível em: http://www.stf.jus.br/portal/inteiroTeor/obterInteiroTeor.asp?id=615361).

Supremo Tribunal Federal. Recurso Extraordinário 466343. Tribunal Pleno. Min. CEZAR PELUSO, Tribunal Pleno, julgado em 03/12/2008, Diário da Justiça, Brasília, DF, 07 jun. 2009. (Disponível em: http://www.stf.jus.br/portal/inteiroTeor/obterInteiroTeor.asp?id=615361).

CAMPOS. G.J. B. Tratado elemental de derecho constitucional argentino. EDIAR: Buenos Aires, 1995.

CANOTILHO,J.J. Gomes. Direito Constitucional, Coimbra, Almedina, 1993.

FERREIRA, Aurélio Buarque de Holanda. Miniaurélio século XXI escolar. 4. ed. rev. e ampl. Rio de Janeiro: Nova Fronteira, 2000

HENKIN, Louis. International Law: cases and materials. Trad. Hugo Brotas. Saraiva: São Paulo, 2002.

MAZZUOLI, Valério de Oliveira. Direito Internacional Público: parte geral. 3ả Ed. São Paulo: RT, 2006

PACTO DE SAN JOSE DA COSTA RICA. Disponível em: <http://www.planalto.gov.br/ccivil_03/decreto/1990-1994/anexo/and678-92.pdf>. Acesso em: 17 de março de 2016.

PEREIRA, Jane Reis Gonçalves . Apontamentos sobre a aplicação das normas de direito fundamental nas relações jurídicas entre particulares. In: BARROSO, Luís Roberto. (Org.). A nova interpretação constitucional: ponderação, direitos fundamentais e relações privadas. 2ed.Rio de Janeiro: Renovar, 2006

PIOVESAN, Flávia. A Constituição de 1988 e os Tratados Internacionais dos Direitos Humanos. 1996. Disponível em: < http://www.pge.sp.gov.br/centrodeestudos/revistaspge/revista3/rev6.htm>. Acesso em: 17 de março de 2016.

SARLET, Ingo Wolfgang. A Eficácia dos Direitos Fundamentais. Porto Alegre: Livraria do Advogado, 2007.

SANTOS, Boaventura. Conhecimento prudente para uma vida decente: um discurso sobre as ciências revisitado. São Paulo: Cortez, 2004

A gramática do tempo: para uma nova cultura política. São Paulo: Cortez, 2006.

SILVA, De Plácido e. Vocabulário Jurídico. 27. ed. rev. atual. Rio de Janeiro: Forense, 2007.

YÚDICE, George. A conveniência da cultura: usos da cultura na era global. Tradução de Marie-Anne Kremer. Belo Horizonte: Editora da UFMG, 2004. 
Quaestio Iuris

Trabalho enviado em 13 de setembro de 2016. Aceito em 16 de abril de 2017. vol. 11, no. 01, Rio de Janeiro, 2018. pp. 529-547 DOI: $10.12957 /$ rqi.2018.25562 